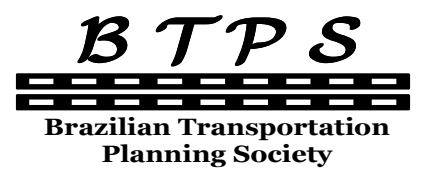

Planning Society
Journal of Transport Literature

Vol. 7, n. 1, pp. 194-201, Jan 2013

Reviews \& Essays
JTL | RELIT

www.transport-literature.org ISSN 2238-1031

\title{
A importância do direito marítimo e da regulação dos transportes e portos para o desenvolvimento da logística
}

[The important role of maritime law and regulation of transportation and ports to the development of logistics]

Wesley O. Collyer*

Universidade do Vale do Itajaí (UNIVALI), Brazil

Submitted 27 Jul 2011; received in revised form 22 Nov 2011; accepted 26 Jan 2012

\begin{abstract}
Resumo
O crescimento da atividade econômica brasileira, especialmente a partir da redução da inflação, desde a segunda metade da década de 1990, tem aumentado sobremaneira o comércio exterior brasileiro (MDIC, 2010). Apesar disso, a infraestrutura da logística do comércio exterior ainda se encontra precária, vez que o ambiente institucional ainda é inibidor dos investimentos necessários para a promoção da eficiência no setor, a fim de tornar os produtos brasileiros competitivos. Nesse cenário, 95\% (Antaq, 2010; MDIC, 2010) do comércio exterior brasileiro é realizado pela via aquaviária e passa pelos portos brasileiros, o que tem gerado enorme caos em face dos gargalos no setor. Por sua vez, o Direito Marítimo e o Direito Regulatório dos Transportes e Portos, como disciplinas jurídicas autônomas assumem papel cada vez mais relevante. Para contribuir com a difusão das mesmas, objetiva-se apresentar alguns aspectos desses temas, bem como discorrer sobre os principais assuntos abordados na obra Direito Marítimo, Regulação e Desenvolvimento.
\end{abstract}

Palavras-Chave: direito marítimo; regulação dos transportes; portos; cabotagem.

\section{Abstract}

The development of Brazilian economy, especially after the reduction of inflation in the second period of 1990's, has developed the Brazilian foreign trade (MDIC, 2010). Nevertheless, its logistics are not efficient, and the institutional framework does not contribute to promote the investments and increasing the efficiency in the sector, the way to become Brazilian products more competitive. In this scenario, 95\% (Antaq, 2010; MDIC, 2010) of Brazilian foreign trade is carried using waterways and through the ports. This has caused a big chaos specially due to the bottlenecks in the sector. Thus, Maritime Law and Regulatory Law of Transportation and Ports, as autonomous legal disciplines have achieved an important role. In order to contribute to the diffusion of both, this article aims to present some important aspects of these issues, as well the main themes of the book Direito Marítimo, Regulação e Desenvolvimento.

Key words: maritime law; regulation of transportation; ports; cabotage.

*Email: wocollyer@gmail.com.

\section{Recommended Citation}

Collyer, W. O. (2013) A importância do direito marítimo e da regulação dos transportes e portos para o desenvolvimento da logística. Journal of Transport Literature, vol. 7, n. 1, pp. 194-201.

- JTL/RELIT is a fully electronic, peer-reviewed, open access, international journal focused on emerging transport markets and published by BPTS - Brazilian Transport Planning Society. Website www.transport-literature.org. ISSN 2238-1031. 


\section{Introdução}

$\mathrm{Na}$ atualidade, somente $1 \%$ do comércio exterior brasileiro é transportado em navios de empresas nacionais de navegação e, apesar de o Brasil caminhar para a $5^{\text {a }}$ economia mundial, não possui frota mercante à altura da sua economia, pois se encontra na $31^{\mathrm{a}}$ posição em toneladas de porte bruto $(\mathrm{tpb})$ registrada em bandeira nacional. ${ }^{1}$

Uma das causas do problema é o ambiente institucional, e nele dois elementos estratégicos, como falta de pessoal qualificado para prestar juridicidade ${ }^{2}$ adequada e eficiente ao setor, e física, em face da inexistência de infraestrutura logística e eficaz. ${ }^{3}$

Mas como fazer a intervenção do Estado no domínio econômico (regulação) em setor com tantas autoridades intervenientes?

Para citar um exemplo, somente no setor de transporte aquaviário e portos brasileiro há cerca de trinta autoridades intervenientes, das três esferas de governo, dentre as quais, Antaq (Agência Nacional de Transportes Aquaviários), SEP (Secretaria Especial de Portos), Receita Federal, Marinha do Brasil, IBAMA, Tribunal de Contas da União, Polícia Federal, Anvisa (Agência Nacional de Vigilância Sanitária) e Secretarias Estaduais da Fazenda.

Além disso, apesar da edição das Leis n. 8.630/93 (Lei dos Portos), nº 9.432/97 (ordena o tráfego aquaviário) e $n^{\circ}$ 10.233/2001 (cria a Agência Nacional de Transportes Aquaviários Antaq) e de outras normas infraconstitucionais que regulam o setor de transportes aquaviários

\footnotetext{
${ }^{1}$ UNCTAD. United Nations Conference on Trade and Development. Review of Maritime Transport 2010. New York and Geneva: United Nations, 2010.

${ }^{2}$ Aqui conceituada como método de produção, interpretação e aplicação do direito. O Programa de Mestrado e Doutorado em Ciência Jurídica dispõe de um Grupo de Pesquisas, Regulação da Infraestrutura e Juridicidade da Atividade Portuária, registrado no CNPq, coordenado pelo organizador da obra Direito Marítimo, Regulação e Desenvolvimento, Prof. Dr. Osvaldo Agripino de Castro Junior.

${ }^{3}$ Sobre o tema: CASTRO JUNIOR, Osvaldo Agripino de. Direito Regulatório e Inovação nos Transportes e Portos nos Estados Unidos e Brasil, prefácio do Prof. Ashley Brown da Harvard University, Conceito Editorial, 2009; CASTRO JUNIOR, Osvaldo Agripino de. (org.); PASOLD, Cesar Luiz. (orgs.) Direito Portuário, Regulação e Desenvolvimento, $2^{\mathrm{a}}$ edição. Belo Horizonte: Fórum, 2010 e Direito Marítimo, Regulação e Desenvolvimento, prefaciado pelo Prof. Wesley Collyer. Belo Horizonte: Fórum, 2011.
} 
e portos, observa-se, ainda, grande insegurança jurídica entre os agentes econômicos que fazem uso do binômio navio-porto, bem como os que se submetem ao controle aduaneiro, exercido pela Receita Federal.

Mencione-se que, no controle aduaneiro, tem se observado dois problemas: a criminalização dos agentes do comércio exterior e a violação dos princípios da razoabilidade, da proporcionalidade e da eficiência pelos auditores da Receita Federal.

Assim, como tornar tal ambiente eficiente? Nesse quadro, a regulação setorial independente, exercida pela Antaq pode ser útil.

Acrescente-se, ainda, que somente a partir de 2006, a citada agência reguladora começou a funcionar com maior eficácia, de modo que, ainda há falta de maior compreensão das suas competências, o que tem provocado a judicialização dos conflitos da regulação setorial e geração de externalidades negativas e manutenção ou aumento dos gargalos logísticos do setor.

Sustenta-se, contudo, que um dos motivos da insegurança acima é a crise que vive o ensino jurídico brasileiro, com a falta de professores qualificados para ministrar disciplinas que regulam o setor e de pesquisadores para fazer produção científica de qualidade, com o objetivo de desenvolver as indústrias marítimas (transporte), portuária e da construção naval.

\section{Conceitos relevantes}

Diante desse cenário, disciplinas como Direito Marítimo e Direito Regulatório dos Transportes e Portos podem contribuir para desenvolver o setor. Assim, serão apresentados os seus conceitos e o de Logística, a fim de melhor compreensão do tema.

O Direito Marítimo é o conjunto de normas jurídicas que disciplinam as atividades necessárias para que as embarcações efetuem o transporte pela via aquaviária. Trata-se, portanto, de disciplina jurídica autônoma que possui, inclusive, em face da sua relevância, assento constitucional (art. 22, inciso I, da CF/88). Seu principal objeto regular as relações 
jurídicas que se dão em torno do navio, ${ }^{4}$ aqui considerado espécie de embarcação, ${ }^{5}$ por meio das relações jurídicas que se dão através dos contratos de transportes ${ }^{6}$ e de afretamento de embarcações, hipoteca naval, ${ }^{7}$ registro de embarcação, ${ }^{8}$ dentre outras.

Por sua vez, o Direito Regulatório do Transporte Aquaviário e da Atividade Portuária é a disciplina jurídica que tem como objeto regular as relações jurídicas que cuidam da efetividade do marco regulatório do setor. A citada disciplina tem como fontes principais de Direito a Lei n. 10.233/2001, que criou a Antaq e o Conit (Conselho Nacional de Integração de Políticas de Transportes), bem como as Leis n. 8.630/93 (Lei dos Portos) e Lei n. 9432/97, que dispõe sobre a ordenação do tráfego aquaviário.

Nesse sentido, é relevante conceituar logística. A palavra logística tem origem no grego logos $(\lambda o ́ \gamma o \varsigma)$ e significa "discurso, razão, rácio, racionalidade, linguagem, frase", mais especificamente da palavra grega logistiki ( organização financeira.

No idioma francês resultou em loger - alojar ou acolher - e foi inicialmente usada para descrever a ciência da movimentação, suprimento e manutenção de forças militares no

\footnotetext{
${ }^{4}$ Possui três requisitos não comuns a todas as embarcações: robustez, estanqueidade e vencer as fortunas do mar. Como espécie do gênero embarcação, todo navio é embarcação, mas nem toda embarcação é navio. Essa diferença é relevante, especialmente quando se trata de competência, tal como o art. 109, IX, da CF/88: "Art. 109 - Aos juizes federais compete processar e julgar: IX - os crimes cometidos a bordo de navios ou aeronaves, ressalvada a competência da Justiça Militar." Nesse caso, deve-se ter cautela, pois um crime ocorrido a bordo de uma embarcação de recreio, como iate ou lancha, não será julgado na Justiça Federal, por não se tratar de navio, mas de embarcação, sendo cabível o julgamento pela Justiça Estadual.

${ }^{5}$ Segundo o art. $2^{\circ}$, inciso V da Lei n. 9.537, de 11 de dezembro de 1997, que dispõe sobre a segurança do tráfego aquaviário em águas sob jurisdição nacional e dá outras providências (Lei de Segurança do Tráfego Aquaviário - LESTA): "V - Embarcação - qualquer construção, inclusive as plataformas flutuantes e, quando rebocadas, as fixas, sujeitas à inscrição na autoridade marítima e suscetível de se locomover na água, por meios próprios ou não, transportando pessoas ou cargas."

${ }^{6}$ Considerado como aquele celebrado entre o embarcador (shipper) e o transportador (carrier) por meio do qual este se obriga, sob sua custódia, a transportar pela via aquaviária, de um porto a outro, mercadoria ou pessoa, e aquele se obriga a pagar uma remuneração por esse serviço, denominado frete.

${ }^{7}$ É efetuada no Tribunal Marítimo, conforme Lei ${ }^{\circ}$ 2.180/54.

${ }^{8}$ Nos termos do art. $2^{\circ}$, inciso XVIII da LESTA: "Registro de Propriedade da Embarcação - registro no Tribunal Marítimo, com a expedição da Provisão de Registro da Propriedade Marítima;"
} 
terreno. Depois disso, foi usada para descrever a gestão do fluxo de materiais numa organização, desde a matéria-prima até os produtos acabados.

No Brasil, a "nossa" logística tem deixado a desejar. O expressivo aumento da produção agrícola e as obras de infraestrutura de transportes para a Copa do Mundo (2014) e Olímpiadas (2016), não vêm, contudo, sendo acompanhadas de uma regulação do setor de transportes que possa fazer face a essa demanda de forma eficiente.

\section{A importância do Direito Marítimo e do Direito Regulatório dos Transportes e Portos para o Desenvolvimento da Logística}

Deve-se ressaltar que os setores de transporte aquaviário, portos e comércio exterior, pela natureza internacional das atividades, sofrem intensa regulação supranacional realizada por meio de tratados editados pelos organismos internacionais.

Dentre tais entidades, podem ser citadas a International Maritime Organization (IMO), que regula a segurança da navegação marítima e a proteção do meio ambiente marinho; a Organização Mundial do Comércio (OMC), que regula as normas de Direito Internacional Econômico, com forte impacto no controle aduaneiro e nas medidas de defesa comercial; a Organização Mundial das Aduanas (OMA), que regula o controle aduaneiro e a aplicação das medidas de defesa comercial, dentre as quais o antidumping e salvaguardas; e a Organização Internacional do Trabalho (OIT), que trata das normas de proteção ao trabalho marítimo e portuário.

Pode-se, ainda, citar a UNCTAD (United Nations Conference on Trade and Development) ${ }^{9} \mathrm{e}$ a UNCITRAL (United Nations Commission on International Trade Law) que tratam do comércio e desenvolvimento e do Direito do Comércio Internacional, respectivamente.

Diante desse cenário e, em face da complexidade e alto grau de expertise das matérias que regulam o setor, é necessário contribuir para a difusão de tais normas, por meio da difusão de conteúdos poucos explorados das disciplinas jurídicas como Direito Marítimo e Direito

\footnotetext{
${ }^{9}$ UNCTAD. United Nations Conference on Trade and Development. Review of Maritime Transport 2008. Report by UNCTAD Secretariat. New York and Geneva: United Nations, 2008, p. xiii.
} 
Regulatório do Transporte e Portos, e pela possibilidade de redução de risco na atividade de transporte.

Nesse momento de expansão da demanda por embarcações em função do pré-sal, transportes hidroviário interior e cabotagem, bem como aumento da dependência dos usuários brasileiros por transporte internacional, é relevante o estudo da regulação setorial independente.

Assim, a opção ideológica do organizador da obra não deve ser omitida, qual seja: a de que objetiva contribuir para o aperfeiçoamento do Direito Marítimo e da regulação de transportes no Brasil e construção de um Direito Marítimo revigorado, autônomo e dialético.

Essa disciplina deve defender os interesses dos usuários dos serviços, destinatário principal das políticas de transporte, e das empresas de navegação brasileiras e, ao mesmo tempo, estimular a economia, de forma sustentável, por meio da iniciativa privada dos agentes econômicos do setor de transportes brasileiro, e proteger os interesses do país, que tem grande dependência de navios de outras bandeiras.

Esse Direito Marítimo deve ser crítico e de resistência à Lex Maritima, porquanto essa foi capturada pelos interesses dos países que exploram o transporte marítimo, mas não recepcionada com base na ordem pública pátria, naquilo que contraria os interesses dos usuários e empresas de navegação brasileiras.

Dessa forma, o Direito Marítimo brasileiro, deve ser republicano e preservar os princípios da soberania, da cidadania, da dignidade da pessoa humana e dos valores sociais do trabalho e da livre iniciativa, (art. $1^{\circ}$, I a IV, da $\mathrm{CF} / 88$ ), especialmente das micro, pequenas e médias empresas, pela sua grande vulnerabilidade no setor de transportes especialmente o marítimo. ${ }^{10}$

\footnotetext{
${ }^{10}$ Dessa percepção, em face da observância dos requisitos da vulnerabilidade e do destinatário final na relação contratual de transporte marítimo, decorre a tese do uso do Código de Defesa do Consumidor no citado contrato, especialmente quando tais contratos são de adesão e usam tratados não ratificados pelo Brasil. Sobre o tema: FILHO, Orlando de Moraes. A Aplicação do Código de Defesa do Consumidor no Contrato de Transporte Marítimo. In: CASTRO JUNIOR, Osvaldo Agripino de. (org.) Direito Marítimo Made in Brasil. São Paulo: Lex Editora, 2007, p. 165-210; CASTRO JUNIOR, Osvaldo Agripino de. O Diálogo entre as Fontes no Direito Marítimo: Código Civil e Código de Defesa do Consumidor. In: CASTRO JUNIOR, Osvaldo Agripino de. (org.) Direito Marítimo Made in Brasil, p. 271-284; LAMY, Eduardo de Avelar. Contrato de Transporte Marítimo Internacional: Competência e Legislação Aplicável. In: CASTRO JUNIOR, Osvaldo Agripino de. (org.) Direito Marítimo Made in Brasil, p. 97-120.
} 
A sua efetividade deve observar a eficácia dos objetivos da República, mormente o desenvolvimento nacional e a erradicação da pobreza, da marginalização e da redução das desigualdades sociais e regionais (art. $3^{\circ}$, II e III, da $\mathrm{CF} / 88$ ) e o princípio da independência nacional (art. $4^{\circ}$, I, da CF/88).

Essa ótica cosmopolita, do direito do setor de transportes brasileiro, não se confunde com o movimento da globalização. Ela procura elementos para uma nova visão, uma abertura, um novo olhar com uma nova lente metodológica, que analisa e procura contribuir para a solução dos problemas e necessidades dos usuários e operadores de transportes brasileiros.

Não é errôneo afirmar que falta maior contribuição para a segurança jurídica do transporte aquaviário (marítimo, fluvial, lacustre) de mercadorias e pessoas no direito brasileiro por meio da difusão de temas relacionados ao Direito Marítimo, à luz da Regulação ${ }^{11}$ e do Direito e Desenvolvimento, ${ }^{12}$ ou seja, que viabilize a efetividade dos objetivos do art. $3^{\circ}$ da Lei Maior. $^{13}$

\section{Conclusão}

Por fim, de acordo com o Plano Nacional de Logística e Transportes (PNLT 2007), o potencial de desenvolvimento do setor de transportes e portos até 2023 será grande.

Nesse quadro, após a obra Direito Portuário, Regulação e Desenvolvimento (2010), o livro Direito Marítimo, Regulação e Desenvolvimento difunde novos enfoques e objetiva suprir

\footnotetext{
${ }^{11}$ Acerca da regulação dos transportes aquaviários e aéreos, bem como portos, numa perspectiva comparada, visando aperfeiçoar as agências federais setoriais brasileiras, quais sejam ANTAQ e ANAC e contribuir com a teoria da regulação brasileira, ver: CASTRO JUNIOR, Osvaldo Agripino de. Direito Regulatório e Inovação nos Transportes e Portos nos Estados Unidos e Brasil. Prefácio Prof. Ashley Brown - Harvard University. Florianópolis: Conceito Editorial, 2009, 410 p.

${ }^{12}$ Visando a reforma do sistema judicial brasileiro, com ênfase no Direito Comparado, Law and Economics (Análise Econômica do Direito) e Direito e Desenvolvimento, fruto do Doutorado do organizador da obra, com período de pesquisas in loco na Stanford Law School, durante o ano de 2000, como Visiting Scholar: CASTRO JUNIOR, Osvaldo Agripino de. Introdução ao Direito e Desenvolvimento - Estudo Comparado para a Reforma do Sistema Judicial. Prefácio do Prof. Dr. Celso Campilongo. Brasília: OAB Nacional, 2004, 855 p.

${ }^{13}$ Art. $3^{\circ}$ Constituem objetivos fundamentais da República Federativa do Brasil: I - construir uma sociedade livre, justa e solidária; II - garantir o desenvolvimento nacional; III - erradicar a pobreza e a marginalização e reduzir as desigualdades sociais e regionais; IV - promover o bem de todos, sem preconceitos de origem, raça, sexo, cor, idade e quaisquer outras formas de discriminação.
} 
uma lacuna no Direito Marítimo e Direito Regulatório brasileiro, na perspectiva de desenvolvimento do transporte marítimo (shipping) por meio de uma Nova Ordem Marítima Mundial.

A obra aborda os seguintes temas: Bandeiras de Conveniência, Brazilian Maritime Law, Cabotagem Brasileira, Direito Ambiental Marítimo, Direito Internacional Econômico (Medidas de Defesa Comercial), Internacional Privado (Contratos Internacionais), Direito do Trabalho Marítimo, IMO e OMC, non vessel operator common carrier (NVOCC), Regulação Econômica de Transporte aquaviário e portos e Salvamento Marítimo.

Dessa forma, nesse momento de expansão da demanda por embarcações em função do présal, transportes hidroviário interior e cabotagem, bem como do conseqüente aumento da dependência dos usuários brasileiros por transporte internacional, creio que a obra será de extrema utilidade para todos, estudiosos e órgãos privados e estatais, que operam embarcações no Brasil.

\section{Referências}

Castro Junior, O. A. (2009) Direito Regulatório e Inovação nos Transportes e Portos nos Estados Unidos e Brasil. Florianópolis: Conceito Editorial, 410 p.

Castro Junior, O. A. (2004) Introdução ao Direito e Desenvolvimento - Estudo Comparado para a Reforma do Sistema Judicial. Brasília: OAB Nacional, 855 p. 